\title{
Relations between the thermal properties and porosity of sediments in the eastern flank of the Juan de Fuca Ridge
}

\author{
Shusaku Goto and Osamu Matsubayashi \\ Institute for Geo-Resources and Environment, National Institute of Advanced Industrial Science and Technology (AIST), \\ Tsukuba Central 7, 1-1-1 Higashi, Tsukuba, Ibaraki 305-8567, Japan \\ (Received November 25, 2008; Revised March 18, 2009; Accepted March 28, 2009; Online published August 31, 2009)
}

\begin{abstract}
The empirical relations of the thermal properties (thermal conductivity, heat capacity, specific heat, and thermal diffusivity) to the porosity and mineral composition of clay and sandy sediments recovered in the eastern flank of the Juan de Fuca Ridge are examined using the observed thermal properties, index properties, and mineral composition of the sediments. Observed thermal conductivity-porosity relations are explained using the geometric mean model. The observed relations of heat capacity and specific heat, respectively, to porosity are given by the arithmetic mean formula. A new model for the sediment thermal diffusivity-porosity relation is proposed based on models of thermal conductivity and heat capacity. This model, expressed by the geometric mean model with a correction function for the porosity and heat capacities of grain sediment and pore-filling fluid, explains the observed thermal diffusivity-porosity relations. These thermal property models are applicable to thermal properties of other sediment lithology types and are useful as standard models for estimating the thermal properties of marine sediment.
\end{abstract}

Key words: Thermal properties, thermal conductivity, thermal diffusivity, heat capacity, specific heat, porosity, marine sediment, mineral composition.

\section{Introduction}

Thermal properties (thermal conductivity, heat capacity, specific heat, and thermal diffusivity) of earth materials are important parameters for modeling the thermal structure and transport of heat and fluid under the ground. These properties in relation to both the porosity and mineral composition of rock, sediment, and soil have been examined, and several empirical models for predicting thermal properties have been proposed (e.g., Drury and Jessop, 1983; Drury, 1987; García et al., 1991; Ochsner et al., 2001). In terms of marine sediment, the respective relations of thermal conductivity to porosity and mineral composition have been discussed (e.g., Woodside and Messmer, 1961), but those of heat capacity, specific heat, and thermal diffusivity to porosity and mineral composition remain poorly understood, primarily because fewer measurements for these thermal properties have been performed on actual marine sediment samples.

The Juan de Fuca Ridge (Fig. 1) generates the oceanic lithosphere west of North America. This ridge presents a barrier to turbidite originating from the neighboring continental margin and, as a result, a thick layer of sediment accumulates on the eastern flank of the Juan de Fuca Ridge. This sediment acts as a hydrological seal, impeding hydrothermal exchange between the oceanic crust and ocean bottom water (Underwood et al., 2005).

The Integrated Ocean Drilling Program (IODP) Expedi-

Copyright (c) The Society of Geomagnetism and Earth, Planetary and Space Sciences (SGEPSS); The Seismological Society of Japan; The Volcanological Society of Japan; The Geodetic Society of Japan; The Japanese Society for Planetary Sciences; TERRAPUB tion 301 was conducted on the eastern flank of the Juan de Fuca Ridge (Fig. 1) to examine fluid pathways in the oceanic crust and to assess the dynamic influence of hydrothermal circulation on oceanic crust evolution (Fisher et al., 2005). The drilling sites during the IODP Expedition 301 were located over the basaltic basement, which has an age of about $3.5 \mathrm{Ma}, 100 \mathrm{~km}$ east of the crest of the Juan de Fuca Ridge. This basaltic basement is characterized by linear basement ridges and troughs oriented subparallel to the spreading center. Site U1301 of the IODP Expedition 301 is located over one of the basement ridges in the area.

During the IODP Expedition 301, sediments composed of turbidite sequences (Units IA and IB) and hemipelagic clay layers (Unit II) (Fig. 2) were cored discontinuously to a depth of $265.3 \mathrm{~m}$ below the seafloor in Hole U1301C at Site U1301. Sediments with the same stratigraphic units were recovered at Site 1026 of the Ocean Drilling Program (ODP) Leg 168 (Shipboard Scientific Party, 1997) 1$2 \mathrm{~km}$ north of Site U1301, along the same basement ridge (Fig. 1). Sediments at these sites show no hydrothermal alteration.

To determine the thermal structure of the sediment column at Site U1301, thermal conductivities of the sediments were measured onboard using the needle-probe method (Von Herzen and Maxwell, 1959; Blum, 1997). Goto and Matsubayashi (2008) analyzed the needle-probe temperature data to measure thermal conductivity during IODP Expedition 301 and estimated three thermal properties: thermal conductivity, heat capacity, and thermal diffusivity.

In the study reported here, we investigate the characteristics of four thermal properties-thermal conductivity, 


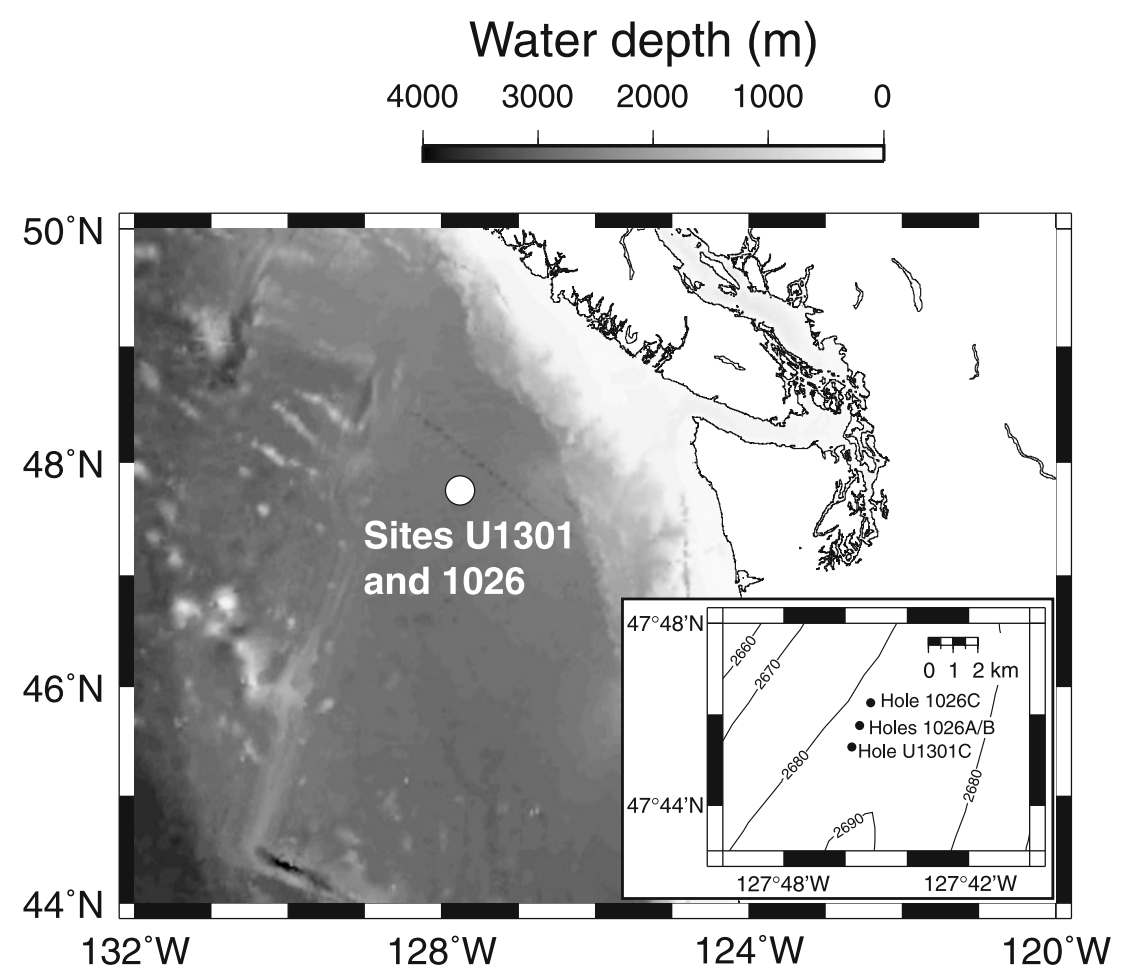

Fig. 1. Bathymetric map of the northern Pacific Ocean (bathymetric data from Sandwell and Smith (1997)). The open circle represents the location of drilling sites of the IODP Expedition 301 and ODP Leg 168. The inset is a location map of drilling holes where sediment cores used for this study were recovered (bathymetric data from Shipboard Scientific Party (1997)).

heat capacity, specific heat, and thermal diffusivity—of sediments at Site U1301 using data on the thermal properties and index properties (porosity and bulk density) of the sediments at the site. We also examine the empirical relations of these thermal properties to the porosity and mineral composition of the sediments in the linear basement ridge and trough area using the thermal and index properties and the mineral composition observed for sediments at Sites U1301 and 1026 in the area.

\section{Thermal Properties of Sediments at Site U1301 in the Eastern Flank of the Juan de Fuca Ridge}

During the IODP Expedition 301, sediments were classified based on visual descriptions and on basic texture'clay', 'sand', or 'mixed' lithology-in order to elucidate the relations between the measured physical properties and sediment lithology (Expedition 301 Scientists, 2005). The designation 'clay' refers to clay-silt, and 'mixed' lithology refers to sandy silt-silty sand. These lithological categories are used in this study.

\subsection{Previous studies of thermal properties of sediments at Site U1301}

Goto and Matsubayashi (2008) estimated the thermal conductivity, heat capacity, and thermal diffusivity of sediments that had been classified according to these three lithological categories as follows. First, thermal conductivity was estimated from needle-probe temperature data using an asymptotic approximation formula that expresses the temperature rise of the needle-probe (Von Herzen and Maxwell, 1959; Blum, 1997). Using the estimated thermal conductivity as a constant parameter, the heat capacity is inverted from the needle-probe temperature data using a complete formula expressing the temperature rise of the needle-probe (Blackwell, 1954; Jaeger, 1956). Finally, thermal diffusivity is calculated from the estimated thermal conductivity and heat capacity.

Goto and Matsubayashi (2008) also proposed the following empirical relations of thermal conductivity $K_{\mathrm{s}}$ to thermal diffusivity $\kappa_{\mathrm{s}}$ and heat capacity $\rho_{\mathrm{s}} c_{\mathrm{s}}$.

$$
\begin{aligned}
\kappa_{\mathrm{s}} & =-0.176+2.284 K_{\mathrm{s}}+0.763 K_{\mathrm{s}}^{2} \\
\rho_{\mathrm{s}} c_{\mathrm{s}} & =\frac{10 K_{\mathrm{s}}}{-0.176+2.284 K_{\mathrm{s}}+0.763 K_{\mathrm{s}}^{2}} \\
\kappa_{\mathrm{s}} & =-0.279+2.659 K_{\mathrm{s}}+0.434 K_{\mathrm{s}}^{2}
\end{aligned}
$$

The units of $K_{\mathrm{s}}, \kappa_{\mathrm{s}}$, and $\rho_{\mathrm{s}} c_{\mathrm{S}}$ in these equations are, respectively, $\mathrm{W} \mathrm{m}{ }^{-1} \mathrm{~K}^{-1}, 10^{-7} \mathrm{~m}^{2} \mathrm{~s}^{-1}$, and $10^{6} \mathrm{~J} \mathrm{~m}^{-3} \mathrm{~K}^{-1}$. Based on a comparison between observed and calculated thermal diffusivities and heat capacities at Site U1301, the estimation errors are within approximately $8 \%$.

\subsection{Vertical distribution of thermal properties of sedi- ments at Site U1301}

For this study, we newly estimate the specific heat of the sediments at Site U1301 from heat capacity estimated by Goto and Matsubayashi (2008) and bulk density measured by Expedition 301 Scientists (2005) for these three lithological categories in cases where the following two criteria are satisfied: the measurement location of the index properties must be within $30 \mathrm{~cm}$ of the location of the measurement of thermal conductivity, and the sediments in the interval must belong to the same lithological category. Based on these cri- 


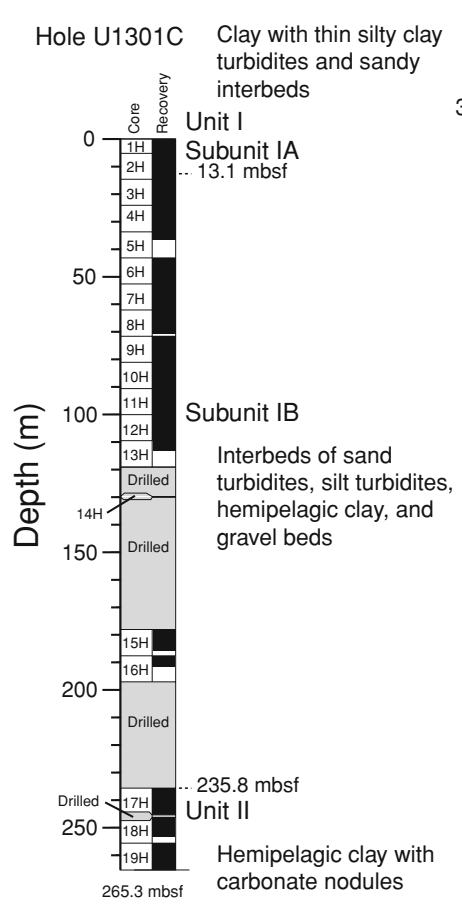

(a)

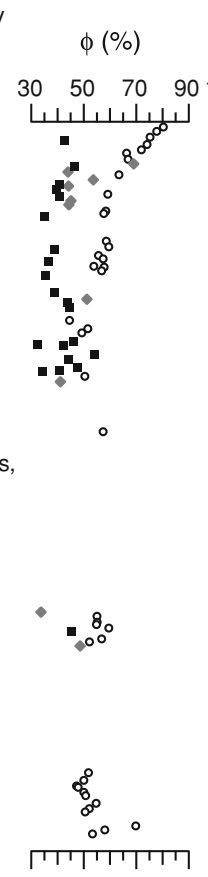

(b)

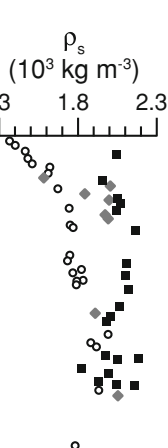

$\circ$
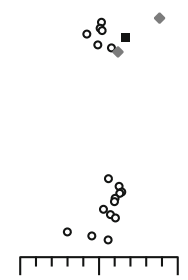

(c)
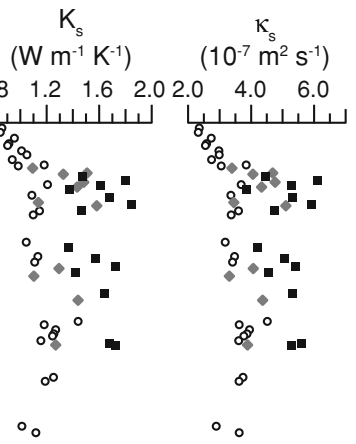

$\rho_{\mathrm{s}} \mathrm{C}_{\mathrm{s}}$

$\mathrm{C}_{\mathrm{s}}$ $\left(10^{6} \mathrm{~J} \mathrm{~m}^{-3} \mathrm{~K}^{-1}\right) \quad\left(10^{3} \mathrm{~J} \mathrm{~kg}^{-1} \mathrm{~K}^{-1}\right)$

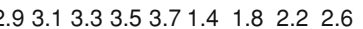

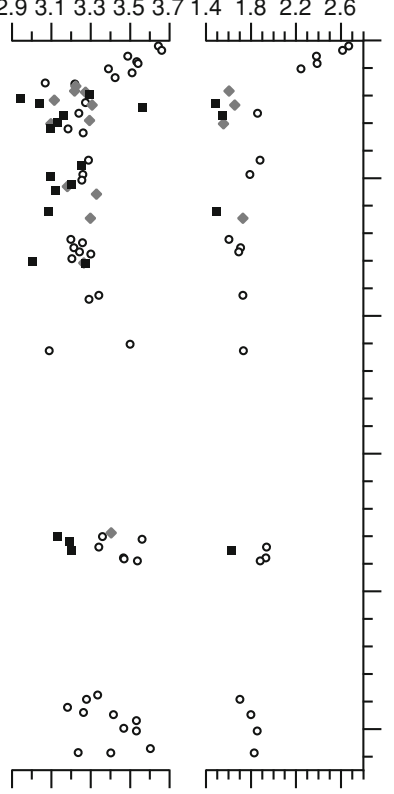

(d)

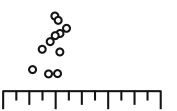

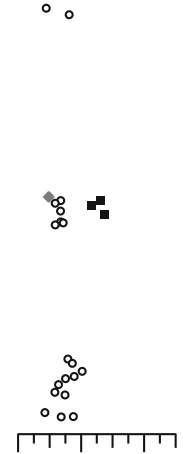

(e) (f)

- Clay - Sand - Mixed

Fig. 2. Lithological units and porosity and thermal properties of sediments recovered from Hole U1301C at Site U1301. Core description and index properties from Expedition 301 Scientists (2005) and thermal conductivity, heat capacity, and thermal diffusivity data from Goto and Matsubayashi (2008). Specific heats are estimated in this study. (a) Core number, amount of recovery, and brief description of lithology; (b) porosity $\phi$; (c) bulk density $\rho_{\mathrm{s}} ;$ (d) thermal conductivity $K_{\mathrm{s}}$; (e) thermal diffusivity $\kappa_{\mathrm{s}}$; (f) heat capacity $\rho_{\mathrm{s}} c_{\mathrm{s}} ;(\mathrm{g})$ specific heat $c_{\mathrm{s}}$.

teria, we found 20 sets of thermal and index property data for clay, four for sand, and four for the mixed lithology that we subsequently used to calculate the specific heat of each set.

Figure 2 depicts the vertical distributions of index properties and thermal properties at Site U1301. All thermal and index properties depend strongly on the lithologies. For clay, porosity decreases systematically with depth down to $100 \mathrm{~m}$ below the seafloor. In the same depth interval, the heat capacity and specific heat decrease with depth. In contrast, the bulk density, thermal conductivity, and thermal diffusivity increase with depth. For sand and mixed lithologies, no clear depth dependence was found for porosity, indicating that, compared with clay, both sand and mixed lithology are resistant to compaction by the accumulation of sediment. Bulk density, thermal conductivity, heat capacity, and thermal diffusivity for sand and mixed lithology also show no depth dependence, corresponding to the porosity distributions. Because of the lack of observed data, depth trends of specific heat for sand and mixed lithology are unknown. Below $100 \mathrm{~m}$, discontinuous core recovery prevents any analysis of trends in the index and thermal properties.

\section{Models of Thermal Properties of Sediments in the Basement Ridge and Trough Area in the Eastern Flank of the Juan de Fuca Ridge}

We report here our study of the empirical relations of thermal properties to the porosity and mineral composition of clay and sand in the linear basement ridge and trough area in the eastern flank of the Juan de Fuca Ridge. At Site U1301, we obtained only 20 sets of thermal property and porosity data for clay and four for sand. Therefore, we also use thermal conductivity and porosity data for sediments recovered at Site 1026 (Fig. 1) of ODP Leg 168 for this purpose.

\subsection{Thermal and index properties and mineral compo- sition of sediments at Site $\mathbf{1 0 2 6}$}

Sediments recovered at Site 1026 show similar stratigraphic units (turbidite bed and hemipelagic mud layers (Units IA and IB) and a similar hemipelagic mud sequence (Unit II)) to those at Site U1301. Lithological characteristics of the sediments at Site 1026 also resemble those of sediments recovered at Site U1301, indicating that these sites are under the constraints of a similar sediment accumulation environment (Shipboard Scientific Party, 1997; Expedition 301 Scientists, 2005). During ODP Leg 168, sediments were classified into 'mud' and 'sand' based on their visual description and basic texture, similar to the classification used by Expedition 301 Scientists (2005) (no mixed lithology was classified during ODP Leg 168) in order to allow a comparison of the measured thermal and physical properties with sediment lithology. The sediment classified as 'mud' in ODP Leg 168 corresponds substantially to the 'clay' classification of the IODP Expedition 301; we therefore refer to the 'mud' as 'clay' hereafter.

At Site 1026, 26 sets of thermal conductivity and porosity data for clay and two sets for sand satisfy our criteria of selecting pairs of thermal and index properties (see Section 2.2). However, no estimates of thermal diffusivity, heat capacity, or specific heat of sediments are available. For this study, we calculate thermal diffusivity $\kappa_{\mathrm{s}}$ and heat capacity $\rho_{\mathrm{S}} c_{\mathrm{s}}$ from observed thermal conductivity $K_{\mathrm{s}}$ using 
Table 1. Index and thermal properties of seawater and major sediment-constituent minerals.

\begin{tabular}{|c|c|c|c|c|c|}
\hline & $\begin{array}{c}\text { Density } \\
10^{3} \mathrm{~kg} \mathrm{~m}^{-3}\end{array}$ & $\begin{array}{l}\text { Thermal conductivity } \\
\qquad \mathrm{W} \mathrm{m}^{-1} \mathrm{~K}^{-1}\end{array}$ & $\begin{array}{c}\text { Thermal diffusivity } \\
10^{-6} \mathrm{~m}^{2} \mathrm{~s}^{-1}\end{array}$ & $\begin{array}{l}\text { Specific heat } \\
\mathrm{J} \mathrm{kg}^{-1} \mathrm{~K}^{-1}\end{array}$ & $\begin{array}{l}\text { Heat capacity } \\
10^{6} \mathrm{~J} \mathrm{~m}^{-3} \mathrm{~K}^{-1}\end{array}$ \\
\hline Quartz & $2.648^{\mathrm{a}}$ & $7.69^{\mathrm{b}}$ & $3.92^{\mathrm{j}}$ & $741^{\mathrm{f}}$ & $1.96^{\mathrm{j}}$ \\
\hline Albite & $2.620^{\mathrm{a}}$ & $2.20^{\mathrm{b}}$ & $1.08^{\mathrm{j}}$ & $776^{\mathrm{f}}$ & $2.03^{\mathrm{j}}$ \\
\hline Anorthite & $2.760^{\mathrm{a}}$ & $1.68^{b}$ & $0.82^{\mathrm{j}}$ & $745^{\mathrm{f}}$ & $2.06^{\mathrm{j}}$ \\
\hline Orthoclase & $2.570^{\mathrm{a}}$ & $2.32^{b}$ & $1.28^{\mathrm{j}}$ & $707^{\mathrm{f}}$ & $1.82^{\mathrm{j}}$ \\
\hline Muscovite & $2.831^{\mathrm{a}}$ & $2.32^{\mathrm{b}}$ & $1.03^{\mathrm{e}}$ & $796^{\mathrm{j}}$ & $2.25^{\mathrm{j}}$ \\
\hline Smectite & $2.608^{\mathrm{a}}$ & $1.88^{c}$ & $0.91^{\mathrm{j}}$ & $795^{\mathrm{g}}$ & $2.07^{j}$ \\
\hline Chlorite & $2.800^{\mathrm{a}}$ & $5.15^{d}$ & $2.25^{\mathrm{e}}$ & $818^{\mathrm{j}}$ & $2.29^{j}$ \\
\hline Calcite & $2.710^{\mathrm{a}}$ & $3.59^{\mathrm{b}}$ & $1.62^{\mathrm{j}}$ & $820^{\mathrm{f}}$ & $2.22^{\mathrm{j}}$ \\
\hline Pyrite & $5.011^{\mathrm{a}}$ & $19.21^{\mathrm{b}}$ & $7.40^{\mathrm{j}}$ & $518^{\mathrm{i}}$ & $2.60^{\mathrm{j}}$ \\
\hline Seawater & $1.024^{\mathrm{j}}$ & $0.596^{\mathrm{h}}$ & $0.146^{\mathrm{h}}$ & $3993^{\mathrm{h}}$ & $4.09^{\mathrm{i}}$ \\
\hline
\end{tabular}

a Johnson and Olhoeft (1984); ${ }^{\mathrm{b}}$ Horai and Simmons (1969); ${ }^{\mathrm{c}}$ Brigaud and Vasseur (1989); ${ }^{\mathrm{d}}$ Horai (1971); ${ }^{\mathrm{e}}$ Drury (1987); ${ }^{\mathrm{f}}$ Drury et al. (1984); ${ }^{\mathrm{g}}$ Skauge et al. (1983); ${ }^{\mathrm{h}}$ Kaye and Laby (1986); ${ }^{\mathrm{i}}$ Robie et al. (1978); ${ }^{\mathrm{j}}$ Calculated from other properties.

Table 2. Mean volume fraction of minerals of sediments recovered at Site 1026.

\begin{tabular}{lrrrrrr}
\hline \multirow{2}{*}{ Sediment type } & \multicolumn{5}{c}{ Volume fraction (\%) } \\
\cline { 2 - 7 } & \multicolumn{1}{c}{ Smectite } & \multicolumn{1}{c}{ Mica } & Chlorite & Quartz & Feldspar & Calcite \\
\hline \hline Clay*1 $_{\text {Sand }}^{* 2}$ & $24.29 \pm 4.79$ & $13.14 \pm 3.32$ & $9.90 \pm 2.61$ & $26.29 \pm 3.16$ & $23.29 \pm 3.83$ & $1.02 \pm 1.47$ \\
\hline
\end{tabular}

${ }^{* 1}$ Referred to as "mud" by Shipboard Scientific Party (1997).

*2 Referred to as "turbidite sand" by Shipboard Scientific Party (1997).

Table 3. Grain thermal properties, as estimated from observed thermal property-porosity relations of sediments at Sites 1026 and U1301 and predicted from mineral composition of sediments at Site 1026.

\begin{tabular}{|c|c|c|c|c|}
\hline Sediment & $\begin{array}{l}\text { Thermal conductivity } \\
\qquad \mathrm{W} \mathrm{m}{ }^{-1} \mathrm{~K}^{-1}\end{array}$ & $\begin{array}{c}\text { Thermal diffusivity } \\
10^{-6} \mathrm{~m}^{2} \mathrm{~s}^{-1}\end{array}$ & $\begin{array}{l}\text { Specific heat } \\
\mathrm{J} \mathrm{kg}^{-1} \mathrm{~K}^{-1}\end{array}$ & $\begin{array}{l}\text { Heat capacity } \\
10^{6} \mathrm{~J} \mathrm{~m}^{-3} \mathrm{~K}^{-1}\end{array}$ \\
\hline Clay (observed) & $2.99 \pm 0.81$ & $1.41 \pm 0.54$ & $828 \pm 137$ & $2.25 \pm 0.37$ \\
\hline Clay (mineral composition*1) & $3.40 \pm 0.15^{* 2}$ & $1.64 \pm 0.07^{* 2}$ & $758 \pm 10^{* 2}$ & $2.07 \pm 0.01^{* 2}$ \\
\hline Sand (observed) & $3.54 \pm 0.46$ & $1.55 \pm 0.25$ & $881 \pm 27$ & $2.38 \pm 0.11$ \\
\hline Sand (mineral composition*1) & $3.59 \pm 0.28$ & $1.78 \pm 0.15$ & $751 \pm 8$ & $2.02 \pm 0.02$ \\
\hline
\end{tabular}

${ }^{* 1}$ Shipboard Scientific Party (1997); ${ }^{* 2}$ Goto and Matsubayashi (2008).

Eqs. (1)-(4) for clay and sand. Specific heat $c_{\mathrm{s}}$ is calculated from $\rho_{\mathrm{s}} c_{\mathrm{s}}$ calculated using the equations presented above and the bulk density $\rho_{\mathrm{s}}$ measured onboard (Shipboard Scientific Party, 1997).

We also use the mineral composition of clay (originally called 'mud') and sand at Site 1026 determined during ODP Leg 168 (Shipboard Scientific Party, 1997) because (1) the mineral composition of sediments at Site U1301 was not determined during the IODP Expedition 301; (2) Site 1026 is close to Site U1301 (Fig. 1); (3) the lithological characteristics of the sediments at Site 1026 resemble those of sediments recovered at Site U1301 (Shipboard Scientific Party, 1997; Expedition 301 Scientists, 2005). The thermal properties of major and minor sediment-constituent minerals are presented in Table 1. The grain thermal properties estimated from observed thermal property-porosity relations and predicted from the mineral composition of sediments at Site 1026 (Table 2), both of which are discussed later in this report, are presented in Table 3.

\subsection{Thermal properties of clay}

3.2.1 Thermal conductivity The thermal conductivity of a material depends on the direction of the medium and the grain arrangement. Unconsolidated water-saturated marine sediment, however, can be treated as an aggregate in which the sediment grains are both oriented and distributed randomly. Thermal conductivity of an aggregate is well modeled by the geometric mean model, which was first proposed by Woodside and Messmer (1961) as

$$
K_{\mathrm{s}}=K_{\mathrm{w}}^{\phi} K_{\mathrm{g}}^{1-\phi},
$$

where $\phi$ is the fractional porosity, $K_{\mathrm{w}}$ is the thermal conductivity of seawater that fills pore spaces in the sediment, and $K_{\mathrm{g}}$ is the thermal conductivity of the grain sediment. This model was generalized for the thermal conductivity of $N$ mineral component aggregate by Drury and Jessop (1983) as

$$
K_{\mathrm{g}}=\prod_{j=1}^{N} K_{j}^{V_{j}} \quad\left(\sum_{j=1}^{N} V_{j}=1\right),
$$

where $K_{j}$ and $V_{j}$ represent the thermal conductivity and volume fraction, respectively, of the $j$-th mineral. Because of its mathematically simple form, the empirical formula has been widely used to calculate sediment thermal conductivity as a function of porosity and mineral composition (e.g., Kinoshita, 1994; Goto and Matsubayashi, 2008).

Figure 3(a) shows plots of thermal conductivity versus porosity for clay sediments at Sites U1301 and 1026. The thermal conductivity data at Site 1026 vary widely and are 

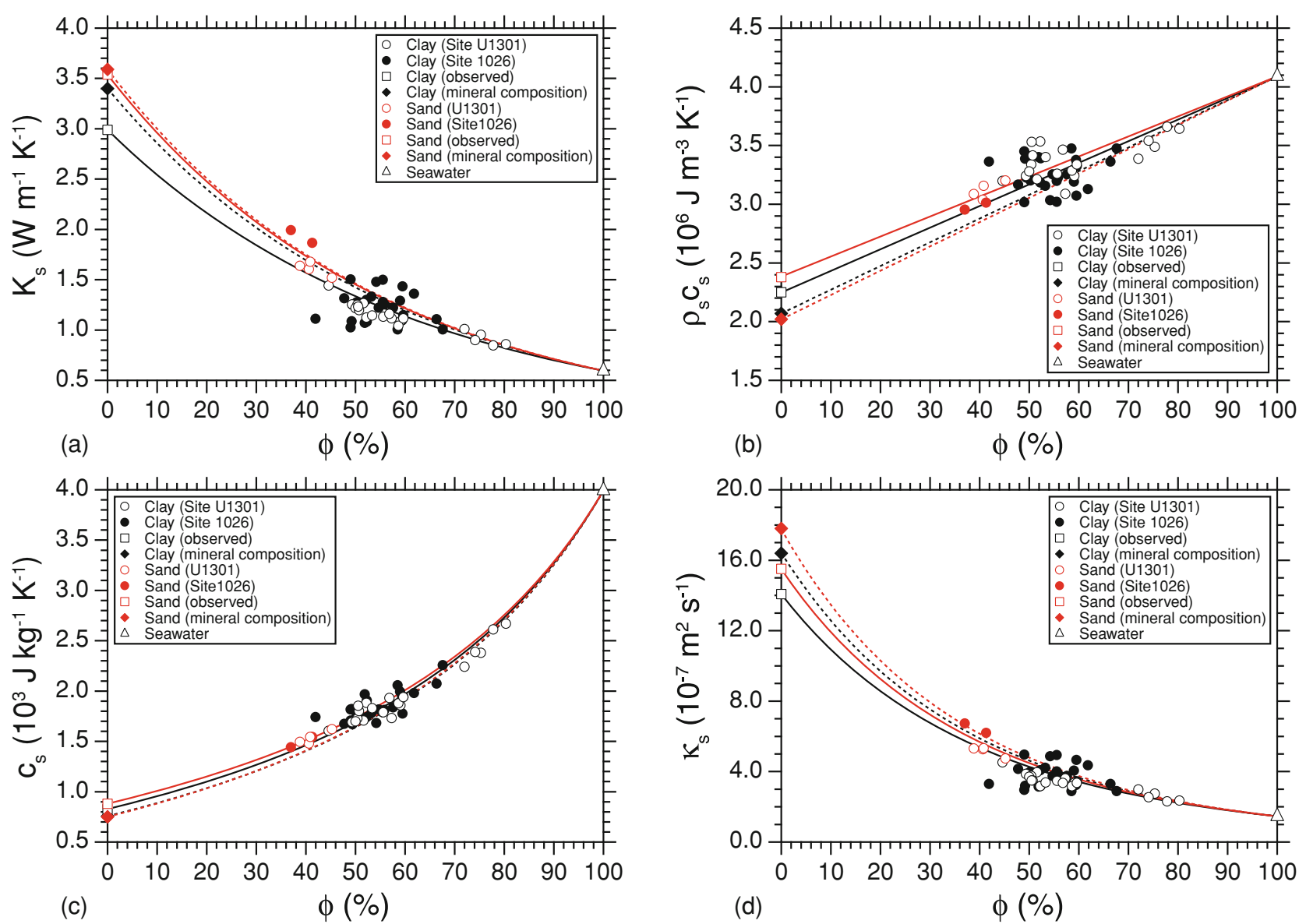

Fig. 3. Relations between porosity and thermal properties. Solid lines and curves represent thermal property-porosity relations for clay (black) and sand (red), as estimated from the observed relations. Dashed lines and curves represent thermal property-porosity relations for clay (black) and sand (red), as predicted from these mineral compositions at Site 1026. Each observed grain thermal property for clay and sand is calculated from its observed thermal property-porosity relation data at Sites U1301 and 1026. (a) Thermal conductivity vs. porosity; (b) heat capacity vs. porosity; (c) specific heat vs. porosity; specific heat-porosity relation predicted from the mineral composition of clay is overlain by that predicted from the mineral compositions of sand; (d) thermal diffusivity vs. porosity.

apparently slightly higher than those at Site U1301. It is possible to estimate the grain thermal conductivity by fitting Eq. (5) to the plots and extrapolating the fitting result. Thermal conductivity data with a wide range of porosity values must be used to do this because the nonlinearity of Eq. (5) impedes an accurate estimation of the grain thermal conductivity. The porosity data on the clay samples used for this study, indicating a range of $40-80 \%$, are insufficient to estimate the grain thermal conductivity accurately through extrapolation. In this study, we first calculate the grain thermal conductivity value for each of the sets of thermal conductivity and porosity using Eq. (5) and then calculate the mean value of the grain thermal conductivity values. The mean value of grain thermal conductivity calculated from individual observed conductivities at Sites U1301 and 1026 is $2.99 \pm 0.81 \mathrm{~W} \mathrm{~m}^{-1} \mathrm{~K}^{-1}$. Using Eq. (6), Goto and Matsubayashi (2008) predicted the conductivity from the mineral composition of clay at Site 1026 as $3.40 \pm 0.15 \mathrm{~W} \mathrm{~m}^{-1}$ $\mathrm{K}^{-1}$, which is higher than that estimated from the observed thermal conductivity-porosity relations. However, a thermal conductivity-porosity relation curve calculated from the mineralogy-based grain thermal conductivity value also fits to the observed thermal conductivity-porosity relation data, indicating that a difference of approximately $15 \%$ of grain thermal conductivity is insensitive to the calculation of thermal conductivity of clay with a high porosity (in the present study, $\phi>$ approx. 50\%).

The mean mineralogy-based grain thermal conductivity value for clay is closer to that for sand than that estimated from the observed thermal conductivity and porosity relations for clay (Table 3). The thermal conductivity of clay at Site 1026 is apparently higher than that at Site U1301. The respective thermal conductivities of quartz and pyrite are considerably higher than those of other sediment constituent minerals (Table 1). For sediment at Site 1026, pyrite is the minor mineral (Table 2) and therefore contributes less to the thermal conductivity of the sediment. This fact suggests either that clay at Site 1026 actually contains a higher amount of quartz than clay at Site U1301, or that the clay originates from a possible artifact that was present in some samples classified as "mud" during ODP Leg 168, including those classified as "mixed" during IODP Expedition 301, which might contain higher amounts of quartz than clay (Goto and Matsubayashi, 2008).

3.2.2 Heat capacity and specific heat The heat capacity and specific heat of materials are scalar quantities. The heat capacity of the earth material, which is an aggregate of two-phase components of solid and fluid, is ex- 
pressed arithmetically (García et al., 1991) as

$$
\rho_{\mathrm{s}} c_{\mathrm{s}}=\phi \rho_{\mathrm{w}} c_{\mathrm{w}}+(1-\phi) \rho_{\mathrm{g}} c_{\mathrm{g}}
$$

where $\rho_{\mathrm{g}}, c_{\mathrm{g}}$, and $\rho_{\mathrm{g}} c_{\mathrm{g}}$ represent the density, specific heat, and heat capacity, respectively, of the grain part of the earth material, and where $\rho_{\mathrm{w}}, c_{\mathrm{w}}$, and $\rho_{\mathrm{w}} c_{\mathrm{w}}$ signify the density, specific heat, and heat capacity, respectively, of the fluid that fills in pore spaces in the material. The grain heat capacity of aggregate composed of minerals of $N$-components is expressed using the arithmetic mean formula (Drury et al., 1984)

$$
\rho_{\mathrm{g}} c_{\mathrm{g}}=\sum_{j=1}^{N} V_{j} \rho_{j} c_{j} \quad\left(\sum_{j=1}^{N} V_{j}=1\right)
$$

where $V_{j}, \rho_{j}, c_{j}$, and $\rho_{j} c_{j}$ denote the volume fraction, density, specific heat, and heat capacity, respectively, of the $j$-th mineral. These formulas have been used widely to predict heat capacity. For marine sediment, however, these formulas have not yet been verified using actually observed data.

Figure 3(b) depicts plots of heat capacity versus porosity for clay sediments at Sites U1301 and 1026. The mean grain heat capacity value calculated from the observed heat capacity-porosity relations at Sites U1301 and 1026 is $2.25 \pm 0.37 \times 10^{6} \mathrm{~J} \mathrm{~m}^{-3} \mathrm{~K}^{-1}$, which is consistent with that predicted from mineral composition of clay sediments at Site $1026\left(2.07 \pm 0.01 \times 10^{6} \mathrm{~J} \mathrm{~m}^{-3} \mathrm{~K}^{-1}\right)$ by Goto and Matsubayashi (2008). Both the heat capacity-porosity relation lines calculated from the mineralogy-based and observed grain thermal heat capacity explain the observed heat capacity-porosity relations.

Figure 3(c) presents plots of specific heat versus porosity for clay sediments at Sites U1301 and 1026. The mean value of grain-specific heat calculated from the observed relations between specific heat and porosity at Sites U1301 and 1026 using Eq. (7) is $828 \pm 137 \mathrm{~J} \mathrm{~kg}^{-1} \mathrm{~K}^{-1}$ and is consistent with the grain-specific heat predicted from the mineral composition of clay, $758 \pm 10 \mathrm{~J} \mathrm{~kg}^{-1} \mathrm{~K}^{-1}$ (Goto and Matsubayashi, 2008). The curves of the specific heat and porosity relations calculated from these grain-specific heat values fit the observed specific heat-porosity relations.

3.2.3 Thermal diffusivity To date, the thermal diffusivity model for seawater-saturated sediment has not been presented because of the difficulty in making measurements. Using Eqs. (5) and (7), the thermal diffusivity of sediment is modeled as

$$
\kappa_{\mathrm{s}}=\frac{K_{\mathrm{s}}}{\rho_{\mathrm{s}} c_{\mathrm{s}}}=\frac{K_{\mathrm{w}}^{\phi} K_{\mathrm{g}}^{1-\phi}}{\phi \rho_{\mathrm{w}} c_{\mathrm{w}}+(1-\phi) \rho_{\mathrm{g}} c_{\mathrm{g}}}=f \kappa_{\mathrm{w}}^{\phi} \kappa_{\mathrm{g}}^{1-\phi},
$$

where $\kappa_{\mathrm{w}}$ is the thermal diffusivity of seawater in the pore space of sediment, $\kappa_{\mathrm{g}}$ is the thermal diffusivity of the grain sediment, and $f$ is defined as the following.

$$
\begin{aligned}
& f=\frac{\beta^{\phi}}{1+(\beta-1) \phi} \\
& \beta=\frac{\rho_{\mathrm{w}} c_{\mathrm{w}}}{\rho_{\mathrm{g}} c_{\mathrm{g}}}
\end{aligned}
$$

Equation (9) expresses the thermal diffusivity of sediment using the geometric mean model with a correction function of porosity and heat capacities of seawater and grain sediment. As presented in Table 1, the heat capacity of minerals that compose marine sediment is almost constant $\left(1.8-2.3 \times 10^{6} \mathrm{~J} \mathrm{~m}^{-3} \mathrm{~K}^{-1}\right)$. The use of $\rho_{\mathrm{g}} c_{\mathrm{g}}=2.07 \times 10^{6}$ $\mathrm{J} \mathrm{m}^{-3} \mathrm{~K}^{-1}$ (Goto and Matsubayashi, 2008) and $\rho_{\mathrm{w}} c_{\mathrm{w}}=$ $4.09 \times 10^{6} \mathrm{~J} \mathrm{~m}^{-3} \mathrm{~K}^{-1}$ (Table 1) produces $\beta=2.0$.

Figure $3(\mathrm{~d})$ presents plots of thermal diffusivity versus porosity for clay sediments at Sites U1301 and 1026. The thermal diffusivity data at Site 1026 are calculated from clay thermal conductivity data of the site using Eq. (1). The thermal diffusivity at Site 1026 varies widely and is slightly higher than that at Site U1301, as derived from the same features of thermal conductivity-porosity relations at Site 1026 (Fig. 3(a)). The mean value of grain thermal diffusivity of the clay sediments at Sites U1301 and 1026 is calculated as $1.41 \pm 0.54 \times 10^{-6} \mathrm{~m}^{2} \mathrm{~s}^{-1}$. The thermal diffusivityporosity relation curve using the grain thermal diffusivity value fits the observed thermal diffusivity-porosity relations (Fig. 3(d)). The mean grain thermal diffusivity is estimated as $1.24 \pm 0.47 \times 10^{-6} \mathrm{~m}^{2} \mathrm{~s}^{-1}$ from the observed thermal diffusivity-porosity relations, yielding an underestimation if the simple geometric mean model $(f=1)$ is applied.

The grain thermal diffusivity of the sediment composed of $N$-constituent minerals can be approximated using the following simple geometric mean model because the heat capacity of major sediment-constituent minerals is almost constant (Table 1).

$$
\begin{aligned}
\kappa_{\mathrm{g}} & =\frac{K_{\mathrm{g}}}{\rho_{\mathrm{g}} c_{\mathrm{g}}}=\frac{\prod_{j=1}^{N} K_{j}^{V_{j}}}{\sum_{j=1}^{N} V_{j} \rho_{j} c_{j}}=\frac{\left(\prod_{j=1}^{N}\left(\rho_{j} c_{j}\right)^{V_{j}}\right) \cdot\left(\prod_{j=1}^{N} \kappa_{j}^{V_{j}}\right)}{\sum_{j=1}^{N} V_{j} \rho_{j} c_{j}} \\
& \approx \prod_{j=1}^{N} \kappa_{j}^{V_{j}}\left(\sum_{j=1}^{N} V_{j}=1\right)
\end{aligned}
$$

The grain thermal diffusivity that is calculated using the thermal diffusivity definition $\left(\kappa_{\mathrm{g}}=K_{\mathrm{g}} / \rho_{\mathrm{g}} c_{\mathrm{g}}\right.$ ) from the mineralogy-based grain thermal conductivity and grain heat capacity of clay sediment by Goto and Matsubayashi (2008) is $1.64 \pm 0.07 \times 10^{-6} \mathrm{~m}^{2} \mathrm{~s}^{-1}$. The grain thermal diffusivity predicted using Eq. (12) from the mineral composition of clay at Site 1026 is $1.65 \pm 0.07 \times 10^{-6} \mathrm{~m}^{2} \mathrm{~s}^{-1}$, corresponding to that calculated by Goto and Matsubayashi (2008). These mineralogy-based grain thermal diffusivities are larger than those estimated from the observed thermal diffusivity-porosity relations. However, the thermal diffusivity-porosity relation curve that is calculated from the mineralogy-based grain thermal diffusivity $\left(1.64 \times 10^{-6}\right.$ $\mathrm{m}^{2} \mathrm{~s}^{-1}$ ) using Eq. (9) fits the observed thermal diffusivityporosity relations (Fig. 3(d)), indicating that a difference of approximately $20 \%$ of grain thermal diffusivity is insensitive to a calculation of thermal diffusivity of clay with high porosity (in the present study, $\phi>$ approx. 50\%).

Similarly to the clay thermal conductivity, the mineralogy-based grain thermal diffusivity value is 
closer to that for sand than that estimated from the observed thermal diffusivity and porosity for clay sediment (Table 3), suggesting either that clay sediment at Site 1026 contains a higher amount of quartz than that at Site U1301, or that it is an artifact: some samples categorized as "mud" during ODP Leg 168 contain materials categorized as "mixed" during IODP Expedition 301.

\subsection{Thermal properties of sand}

Sites U1301 and 1026 yielded only six sets of thermal property-porosity relation data. Furthermore, the range of porosity is limited (37-45\%). Consequently, thermal property models for sand cannot be examined in detail. The grain thermal properties of sand estimated from the observed thermal property-porosity relations and predicted from the mineral composition of sand (Table 2) show similar values (Table 3 ) if we adopt the same thermal property model as that used for clay. The observed grain thermal conductivity and diffusivity are distinctly higher than those for clay. On the other hand, the observed grain values of heat capacity and specific heat resemble those of clay. Similar characteristics are apparent for mineralogybased grain thermal properties for clay and sand, indicating the difference in the amounts of quartz between those of sand and clay. The thermal conductivity-porosity relation curve and the thermal diffusivity-porosity relation curve calculated from the mineralogy-based grain thermal properties seem to fit the observed relations. On the other hand, the mineralogy-based heat capacity-porosity relation line and specific heat-porosity relation curve are located slightly lower than the observed relations on the plot, but they do explain the trend of the observed relations. From these results, we infer that the thermal property-porosity relations for sand are also explainable using the same thermal property model as that for clay.

\section{Conclusion}

We examined the characteristics of four thermal properties - thermal conductivity, heat capacity, specific heat, and thermal diffusivity-for sediments recovered at Site U1301 in the eastern flank of the Juan de Fuca Ridge. The results demonstrate that thermal properties of clay sediments depend strongly on the distribution of porosity. The vertical distribution of the thermal properties of sand and mixed lithology is apparently less variable, reflecting the constant porosity distribution of these lithologies with depth.

The empirical relations of the thermal properties to the porosity and mineral composition of the clay and sand in the linear basement ridge and trough area in the eastern flank of the Juan de Fuca Ridge were investigated using data for thermal properties, porosity, and mineral composition of the sediments in the area. For clay, the observed thermal conductivity-porosity relations are explainable using the geometric mean model. The observed heat capacityporosity and specific heat-porosity relations are given by the arithmetic mean formula. Based on the models of thermal conductivity and heat capacity, we have proposed a new sediment thermal diffusivity model that is expressed by the geometric mean formulation with a correction function of porosity and heat capacities of grain sediment and pore-

\section{filling seawater.}

The observed thermal property-porosity relations for sand are explainable using the same models as those used for clay, which suggests that these thermal property models are applicable to thermal properties of sediments of other lithological types. These results will advance our understanding of sediment thermal properties and are expected to be useful as standard models to predict the thermal properties of marine sediment for actual applications in marine geothermal sciences and engineering and laboratory experiments of marine sediment thermal properties.

Acknowledgments. We are indebted to Dr. Masataka Kinoshita and Dr. Hideki Hamamoto for reviews and comments that improved the manuscript. One author (S. Goto) is particularly grateful to the scientists, operational staff, and technical staff for their cooperative work during the IODP Expedition 301.

\section{References}

Blackwell, J. H., A transient-flow method for determination of thermal constants of insulating material in bulk, J. Appl. Phys., 25, 137-144, 1954.

Blum, P., Physical properties handbook: a guide to the shipboard measurement of physical properties of deep-sea cores, ODP Tech. Note, 26, doi:10.2973/odp.tn.26.1997, 1997.

Brigaud, F. and G. Vasseur, Mineralogy, porosity and fluid control on thermal conductivity of sedimentary rocks, Geophys. J., 98, 525-542, 1989.

Drury, M. J., Thermal diffusivity of some crystalline rocks, Geothermics, 16, 105-115, 1987.

Drury, M. J. and A. M. Jessop, The estimation of rock thermal conductivity from mineral content; assessment of techniques, Zentralbl. Geol. Palaeontol., 1, 35-48, 1983.

Drury, M. J., V. S. Allen, and A. M. Jessop, The measurement of thermal diffusivity of rock cores, Tectonophysics, 103, 321-333, 1984.

Expedition 301 Scientists, Site U1301, in A. T. Fisher, T. Urabe and A. Klaus, and the Expedition 301 Scientists, Proc. IODP, 301, College Station, TX (Integrated Ocean Drilling Program Management International, Inc.), doi:10.2204/iodp.proc.301.106.2005, 2005.

Fisher, A. T., T. Urabe, A. Klaus, and the Expedition 301 Scientists, Proc. $I O D P, 301$, College Station, TX (Integrated Ocean Drilling Program Management International, Inc.), doi:10.2204/iodp.proc.301.2005, 2005.

García, A., E. Contreras, and B. Domínguez, Developments in geothermal energy in Mexico-part 33. Simultaneous determination of the thermal properties of geothermal drill cores, Heat Recov. Syst. CHP, 11, 131139, 1991.

Goto, S. and O. Matsubayashi, Inversion of needle-probe data for sediment thermal properties of the eastern flank of the Juan de Fuca Ridge, $J$. Geophys. Res., 113, B08105, doi:10.1029/2007JB005119, 2008.

Horai, K., Thermal conductivity of rock-forming minerals, J. Geophys. Res., 76, 1278-1308, 1971.

Horai, K. and G. Simmons, Thermal conductivity of rock-forming minerals, Earth Planet. Sci. Lett., 6, 359-368, 1969.

Jaeger, J. C., Conduction of heat in an infinite region bounded internally by a circular cylinder of a perfect conductor, Aust. J. Phys., 9, 167-179, 1956.

Johnson, G. R. and G. R. Olhoeft, Density of Rocks and Minerals, in CRC Handbook of Physical Properties of Rocks, Vol. III, edited by R. S. Carmichael, 1-38, CRC Press, Boca Raton, Florida, 1984.

Kaye, G. W. C. and T. H. Laby, Tables of Physical and Chemical Constants and Some Mathematical Functions, 15th ed., 477 pp., Longman, London, 1986.

Kinoshita, M., Estimating of grain thermal conductivity in the turbidite sediment of the Juan de Fuca Ridge, Proc. ODP, Sci. Results, 139, 553558, College Station, TX (Ocean Drilling Program), 1994.

Ochsner, T. E., R. Horton, and T. H. Ren, A new perspective on soil thermal properties, Soil Sci. Soc. Am. J., 65, 1641-1647, 2001.

Robie, R. A., B. S. Hemingway, and J. R. Fisher, Thermodynamic properties of minerals and related substances at $298.15 \mathrm{~K}$ and 1 bar (105 Pascal) pressure and at higher temperatures, U.S. Geol. Surv. Bull., 1452, 298-310, 1978. 
Sandwell, D. T. and W. H. F. Smith, Marine gravity anomaly from Geosat and ERS 1 satellite altimetry, J. Geophys. Res., 102, 10039-10054, 1997.

Shipboard Scientific Party, Rough basement transect (Site 1026 and 1027), Proc. ODP, Init. Repts., 168, College Station, TX (Ocean Drilling Program), 1997.

Skauge, A., N. Fuller, and L. G. Hepler, Specific heats of clay minerals: sodium and calcium kaolinites, sodium and calcium montmorillonites, illite, and attapulgite, Thermochim. Acta, 61, 139-145, 1983.

Underwood, M. B., K. D. Hoke, A. T. Fisher, E. E. Davis, E. Giambalvo, L. Zuhlsdorff, and G. A. Spinelli, Provenance, stratigraphic architecture, and hydrogeologic influence of turbidites on the mid-ocean ridge flank of northwestern Cascadia Basin, Pacific Ocean, J. Sediment. Res., 75 149-164, 2005.

Von Herzen, R. P. and A. E. Maxwell, The measurement of thermal conductivity of deep-sea sediments by a needle-probe method, J. Geophys. Res., 64, 1557-1563, 1959.

Woodside, W. and J. H. Messmer, Thermal conductivity of porous media. I. unconsolidated sands, J. Appl. Phys., 32, 1688-1699, 1961.

S. Goto (e-mail: s.gotou@aist.go.jp) and O. Matsubayashi 